Article

\title{
Mechanistic Study of the Spiroindolones: A New Class of Antimalarials
}

\author{
Bin Zou ${ }^{1, *}$, Peiling Yap ${ }^{1}$, Louis-Sebastian Sonntag ${ }^{1}$, Seh Yong Leong ${ }^{1}$, Bryan K. S. Yeung ${ }^{1}$ \\ and Thomas H. Keller ${ }^{2}$
}

1 Novartis Institute for Tropical Diseases, 10 Biopolis Road, \#05-01 Chromos, Singapore

2 Experimental Therapeutics Centre, 31 Biopolis Drive, \#03-01 Nanos, Singapore;

E-Mail: thkeller@etc.a-star.edu.sg

* Author to whom correspondence should be addressed; E-Mail: bin.zou@novartis.com;

Tel.: +65-6722-2921; Fax: +65-6722-2918.

Received: 4 July 2012; in revised form: 11 August 2012 / Accepted: 16 August 2012 /

Published: 24 August 2012

\begin{abstract}
During the synthesis of the new antimalarial drug candidate NITD609, a high degree of diastereoselectivity was observed in the Pictet-Spengler reaction. By isolating both the $4 E$ and $4 Z$ imine intermediates, a systematic mechanistic study of the reaction under both kinetic and thermodynamic conditions was conducted. This study provides insight into the source of the diastereoselectivity for this important class of compounds.
\end{abstract}

Keywords: malaria; spiroindolones; NITD609; Pictet-Spengler reaction; mechanism

\section{Introduction}

Malaria continues to be a significant global health problem, with an estimated 216 million infections and 655,000 deaths in 2010 alone [1]. In light of increasing resistance to many current antimalarials, and the growing concern over reduced effectiveness of artemisinin-combination therapies in the long term, there is an urgent need for new drug candidates with the potential to replace the artemisinins in the treatment of malaria [2-4].

We recently reported the new antimalarial drug candidate NITD609 (Figure 1), which exhibits excellent oral bioavailability and exceptional efficacy in a rodent malarial model [5]. While the initial discovery of this new chemotype with potent antimalarial activity was welcome, the presence of the quaternary center in the structure was a cause for some concern, since it was unclear whether the 
relative stereochemistry of the two chiral centers could be adequately controlled. This issue became especially critical when it was determined that only a single diastereoisomer exhibited the desired level of antimalarial activity [6].

Figure 1. Structure of NITD609.<smiles>CC1Cc2ccc(Cl)cc2[C@]2(N1)C(=O)[C@H](C)Cc1c2[nH]c2cc(Cl)c(F)cc12</smiles>

The synthesis of NITD609 and its analogues features a highly diastereoselective Pictet-Spengler reaction. In the reaction of rac- $\alpha$-methyltryptamine (1) [6] with 5-chloroisatin (2) (Scheme 1) the formation of the trans diastereoisomer 3a (where the methyl and the carbonyl groups are in a relative trans configuration) was favoured. Although this result was encouraging as the major diastereoisomer 3a was found to contain the most active stereoisomer required for antimalarial activity [6], the source of the stereoselectivity was unclear. In this paper, a mechanistic study of this reaction is reported.

Scheme 1. Diastereoselectivity in the Pictet-Spengler reaction of spiroindolones.
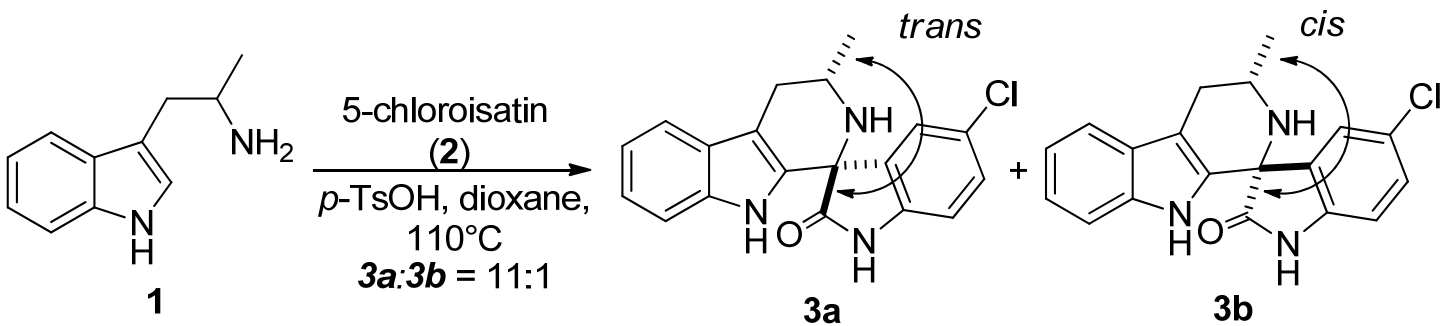

\section{Results and Discussion}

The asymmetric Pictet-Spengler reaction has been widely reported [7-13], and recent literatures have demonstrated very encouraging progress on enantioselective synthesis of this spiroindolone class of compounds using chiral acids as the catalyst $[14,15]$. However, high diastereoselectivity is not often seen in reactions with $\alpha$-methyltryptamines [16-18]. Although the mechanism for the diastereoselective Pictet-Spengler reaction has been studied by a number of groups [19-24], the influence of the imine geometry on the diastereoselectivity has received little attention [25]. Since the importance of imine geometry has been discussed in other types of reactions [26-28], we were tying to investigate the diastereoselectivity source starting from the imine intermediates. An important aspect of our work compared to previous investigations is that the relatively lower reactivity of the imines derived from isatins allowed for the isolation and characterization of imine intermediates, which provided additional insights into the drivers of diastereoselectivity.

Abadi and coworkers reported the synthesis of a series of isatin-derived imines as kinase inhibitors [29]. By adapting the Abadi conditions to our system, we were able to isolate the desired imines in acceptable yield by reacting $\mathbf{1}$ and $\mathbf{2}$ in refluxing ethanol. Moreover optimization of the 
reaction conditions provided access to both imines $\mathbf{4 E}$ (as a $23: 1$ mixture of imines) and $\mathbf{4 Z}$ (1:20) separately (Table 1, entries 1 and 2). The relative stability of the imines allowed us to isolate and assign the configuration of the isomers by NOESY-1D NMR spectroscopy (see Supporting Information) [30].

Table 1. Preparation of imines intermediates.

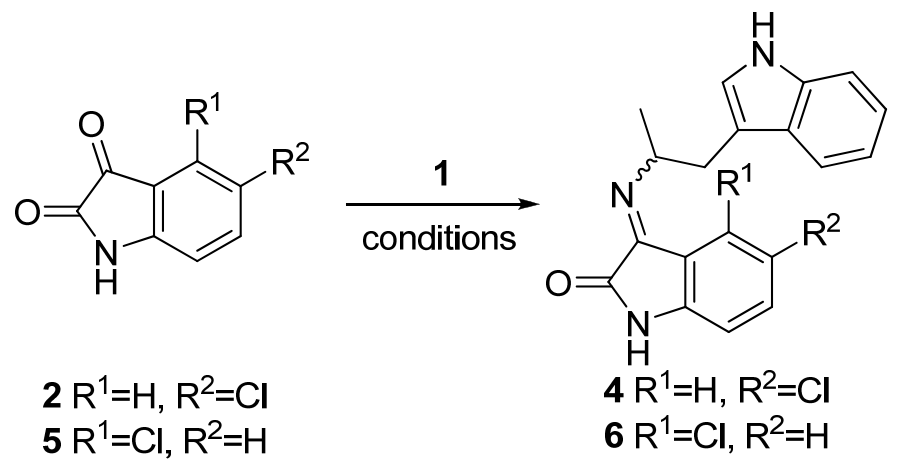

\begin{tabular}{|c|c|c|c|c|}
\hline Entry & Isatin & Conditions $^{a}$ & Yield & Product \\
\hline 1 & 2 & $2.85 \mathrm{M}, \mathrm{EtOH}, 80^{\circ} \mathrm{C}$ & $58 \%$ & $4 E: 4 Z(23: 1)^{b}$ \\
\hline 2 & 2 & $0.95 \mathrm{M}, \mathrm{EtOH}, 80^{\circ} \mathrm{C}$ & $58 \%$ & $4 E: 4 Z(1: 20)^{b}$ \\
\hline 3 & 5 & $0.95 \mathrm{M}, \mathrm{EtOH}, 80^{\circ} \mathrm{C}$ & $55 \%$ & $6 Z^{c}$ \\
\hline
\end{tabular}

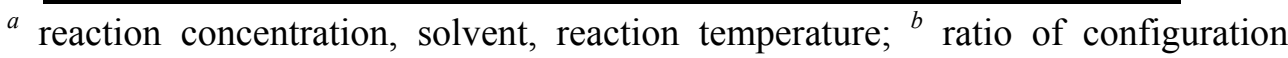
isomers determined by ${ }^{1} \mathrm{H}-\mathrm{NMR} ;{ }^{c} \mathbf{6} \boldsymbol{Z}$ was the sole product observed in ${ }^{1} \mathrm{H}-\mathrm{NMR}$.

Access to both $E$ and $Z$ imine products in virtually pure form was rather fortuitous and seemed to be facilitated by the different physical properties of the two imines. This phenomenon was not studied in detail, however both the $4 E$ and $4 Z$ isomers can be reproducibly prepared by varying the reaction concentration as described in Table 1. Both imines isomerized over $24 \mathrm{~h}$ in DMSO at room temperature to a $1: 3$ mixture of $\mathbf{4 E}: \mathbf{4 Z}$ (Scheme 2). The preference for the $Z$ imine in the thermodynamic mixture can be rationalized by the unfavorable steric interaction between the $\mathrm{H} 4$ of the isatin moiety and $\alpha$-methyltryptamine. Indeed increasing the steric bulk at the 4-position as in 4-chloroisatin (5) only produced $\mathbf{6 Z}$ (Table 1, entry 3 ), which did not isomerize under the described conditions.

Scheme 2. Thermodynamic mixture of imines 4 .<smiles>CC(Cc1c[nH]c2ccccc12)N=C1C(=O)Nc2ccc(Cl)cc21</smiles><smiles>COc1cccc2c(CC(C)N=C3C(=O)Nc4ccc(Cl)cc43)c[nH]c12</smiles>

With the individual $E$ and $Z$ isomers in hand, we turned our attention to the cyclization reaction. Similar diastereoselectivities could be achieved when ethyl acetate was used as the solvent in the reaction shown in Scheme 1, therefore, ethyl acetate was chosen as the solvent since it allowed us to run reactions at low temperature. 
When $4 Z$ was cyclized in the presence of $\mathrm{HCl}(4 \mathrm{~N}$ in 1,4-dioxane, 10 eq.) at three different temperatures, an excellent yield of the corresponding tetrahydro- $\beta$-carboline was obtained (Table 2 , entry 1). In all instances trans isomer 3a was the major product, irrespective of the reaction conditions, although there was a clear trend towards higher diastereoselectivity at lower temperatures. In contrast the cyclization of $\mathbf{4 E}$ at $-78^{\circ} \mathrm{C}$ provided the cis product $\mathbf{3 b}$ preferentially with excellent diastereoselectivity, while higher reaction temperatures led to a reversal of the diastereoselectivity until trans product 3a predominated at $110^{\circ} \mathrm{C}$ (Table 2, entry 2). The same trend was observed when the thermodynamic mixture of imines was cyclized (Table 2, entry 3 ). At low temperature the product ratio was similar to the starting ratio of the imines, while at high temperature the trans product predominated. Finally when $6 \boldsymbol{Z}$ was cyclized, the results were analogous to $\mathbf{4 Z}$ (Table 2 , entry 4 ), the reaction at $-78^{\circ} \mathrm{C}$ providing trans product $7 \mathbf{a}$, but this time with exquisite stereoselectivity, while at $110{ }^{\circ} \mathrm{C}$ the selectivity was reduced to $12: 1$.

Table 2. Diastereoselectivity of the Pictet-Spengler reaction.<smiles>[R2]c1ccc2c(c1[R1])/C(=N\[C@H]([R2])C)C(=O)N2</smiles>

6: $\mathrm{R}_{1}=\mathrm{Cl} ; \mathrm{R}_{2}=\mathrm{H}$
$4 \mathrm{~N} \mathrm{HCl}$ in 1,4-dioxane (10 eq), EtOAc temperatures

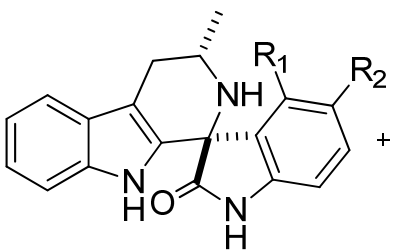

3a (trans): $\mathrm{R}_{1}=\mathrm{H} ; \mathrm{R}_{2}=\mathrm{Cl}$ 3b (cis): $\mathrm{R}_{1}=\mathrm{H} ; \mathrm{R}_{2}=\mathrm{Cl}$ 7a (trans): $\mathrm{R}_{1}=\mathrm{Cl} ; \mathrm{R}_{2}=\mathrm{H} \quad$ 7b (cis): $\mathrm{R}_{1}=\mathrm{Cl} ; \mathrm{R}_{2}=\mathrm{H}$

\begin{tabular}{|c|c|c|c|c|c|}
\hline \multirow{2}{*}{ Entry } & \multirow{2}{*}{ Imine } & \multirow{2}{*}{ Product } & \multicolumn{3}{|c|}{ trans:cis ratio $^{a}{\text { (yield } \%)^{b}}^{b}$} \\
\hline & & & $-78^{\circ} \mathrm{C}^{c}$ & r.t. ${ }^{d}$ & $110^{\circ} \mathrm{C}^{e}$ \\
\hline 1 & $4 E: 4 Z(1: 20)$ & $\mathbf{3 a} / \mathbf{3 b}$ & $18: 1(100)$ & $12: 1(100)$ & $10: 1(83)$ \\
\hline 2 & $4 E: 4 Z(23: 1)$ & $\mathbf{3 a} / \mathbf{3 b}$ & $1: 20(95)$ & $1: 2(100)$ & $7: 1(97)$ \\
\hline 3 & $4 E: 4 Z(1: 3)$ & $\mathbf{3 a} / \mathbf{3 b}$ & $1: 1(100)$ & $3: 1(94)$ & $11: 1(100)$ \\
\hline 4 & $6 Z$ & $7 \mathbf{a} / 7 \mathbf{b}$ & $165: 1(93)$ & $37: 1(98)$ & $12: 1(92)$ \\
\hline
\end{tabular}

${ }^{a}$ ratios determined by HPLC; ${ }^{b}$ isolated yields for trans and cis mixture; ${ }^{c}$ reaction time, $1 \mathrm{~h} ;{ }^{d}$ room temperature; reaction time; $25 \mathrm{~min} ;{ }^{e}$ reaction time, $10 \mathrm{~min}$.

The ability to isolate the imine intermediates allowed us to gain detailed insight into the kinetic control mechanism. The results in Table 2 clearly show that the imine configuration is the major determinant for the diastereoselectivity at $-78^{\circ} \mathrm{C}$. In all cases of kinetic control, the mixture of cis and trans spirotetrahydro- $\beta$-carbolines is basically equivalent to the original ratio of $E$ and $Z$ imines. Based on these results we propose a chair-like transition state for the cyclization step of the Pictet-Spengler reaction (Scheme 3).

The $Z$ imine $S-\mathbf{4} Z$ is first of all protonated under acidic conditions to generated intermediate $S-4 Z^{\prime}$, which can assume two possible conformations, leading to two diastereomeric transition states $\mathbf{A}$ and $\mathbf{B}$, which differ in their face of attack on the imine (Scheme 3). Depending on the conformation of the six-membered transition state the methyl group is either in a pseudoaxial (A) or in a pseudoequatorial (B) position. The pseudoaxial transition state $\mathbf{A}$, is less favored, as it leads to $\mathrm{A}^{1,3}$ strain between the methyl group and the carbonyl of the isatin. Thus, the pseudoequatorial transition state $\mathbf{B}$ is favored, 
which results in the formation of the trans product 8a (a similar mechanism for the cyclization of the $R-4 Z$ enantiomer equally favors the trans product). A similar mechanism for the cyclization of $E$ imine affords cis product $\mathbf{8 b}$ as the major isomer.

Scheme 3. Proposed mechanism for the cyclization of the $S-\mathbf{4 Z}$ imine under kinetic conditions favoring trans product.

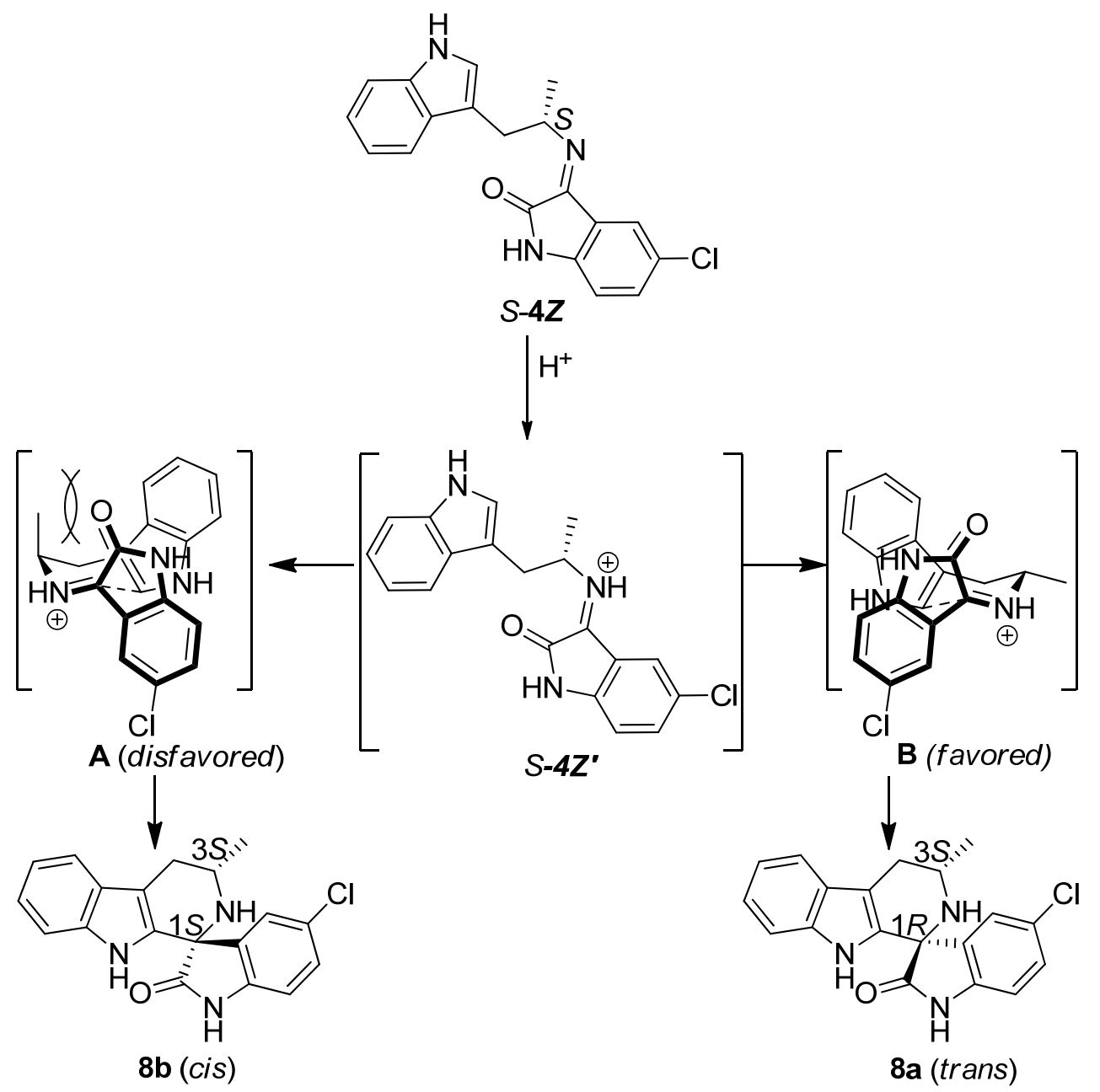

Our findings show that under thermodynamic conditions, the $E: Z$ ratio of the imine does not influence the diastereoselectivity. Isomerization of the imine at high temperatures cannot explain the results in Table 2, as imine $\mathbf{6 Z}$, which due to steric hindrance cannot adopt the $E$ configuration, shows similar diastereoselectivity as imines $4 E$ and $4 Z$. These observations suggest that a different mechanism is responsible for the product distribution. One possible explanation invokes a mechanism similar to the one proposed by Bailey and co-workers [19-21]. Under thermodynamic conditions, bis-spiro intermediates, $\mathbf{E}$ and/or $\mathbf{F}$, are formed independent of the imine geometry ( $\mathbf{E} E$ or $\mathbf{4 Z}$, Scheme 4). The formation of the bis-spiro intermediates is fast and reversible and hence will not influence the stereochemistry of the final products [20]. Instead, bond migration to form the central six-membered ring in intermediates $\mathbf{G}$ and $\mathbf{H}$, is rate determining [20]. The two diastereomeric cations $\mathbf{G}$ and $\mathbf{H}$ differ only in the configuration of the spirocenter, this leads to either the lactam (G) or the chloro-phenyl portion $(\mathbf{H})$ of the isatin to occupy the pseudo-axial position. Of these two possibilities, intermediate $\mathbf{G}$ is favored due to its lower $\mathrm{A}^{1,3}$ strain, leading to $\mathbf{8 a}$ to be the major product formed. 
Scheme 4. Proposed mechanism for the cyclization of the $S$-imine under thermodynamic conditions favoring trans product.<smiles>C[As](C)(C)N=C1C(=O)Nc2ccc(Cl)cc21</smiles>

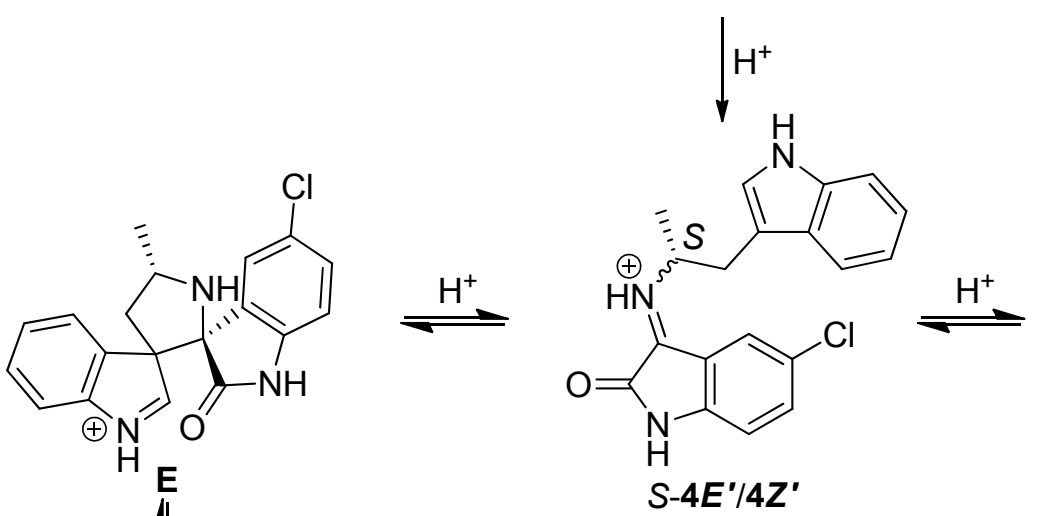<smiles>C[C@@H]1CC2(C(=O)Nc3ccccc32)[C@@]2(C1)C(=O)Nc1ccc(Cl)cc12</smiles>

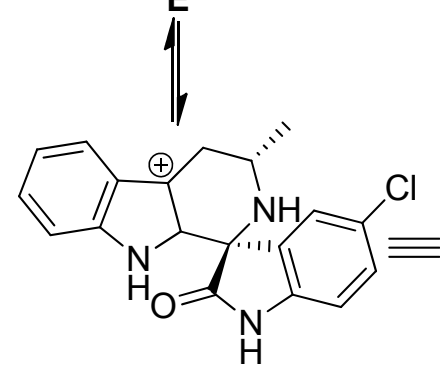

$S-4 E^{\prime} / 4 Z^{\prime}$

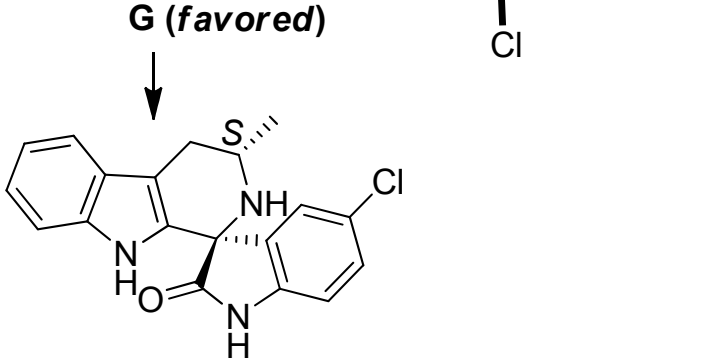

8a (trans)

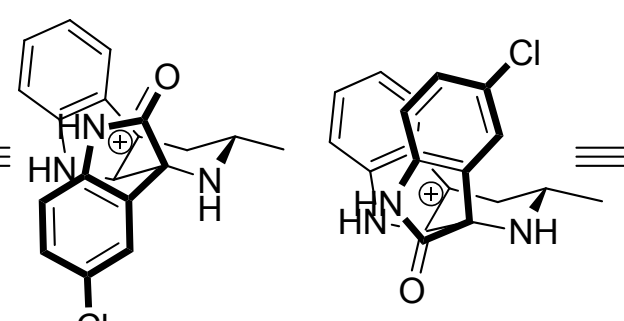

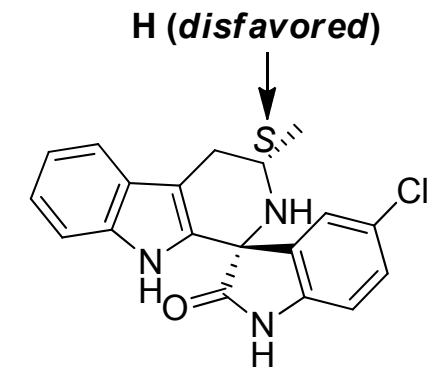

$\mathbf{8 b}(c i s)$

The results observed under thermodynamic control in the Pictet-Spengler reaction could also be explained by the acid catalyzed scission of the C1-N2 bond of the spirocenter (Scheme 5) [8,23,24]. In order to determine whether this isomerization could explain the observed diastereoselectivities, we subjected both the pure $\mathbf{8 a}$ and $\mathbf{8 b}$ isomers to our standard reaction conditions at $110{ }^{\circ} \mathrm{C}$ for extended reaction times $(24 \mathrm{~h})$. Although a slight epimerisation of the spirocenter was observed (Scheme 5), essentially the starting materials remained unchanged. These results suggest that this isomerization is not fast enough to explain the results in Table 2. This is not surprising, since the formation of a carbocation at $\mathrm{C} 1$ leads to a disfavored intermediate (I). 
Scheme 5. A proposed mechanism of isomerization between $\mathbf{8 a}$ and $\mathbf{8 b}$ under acidic conditions.

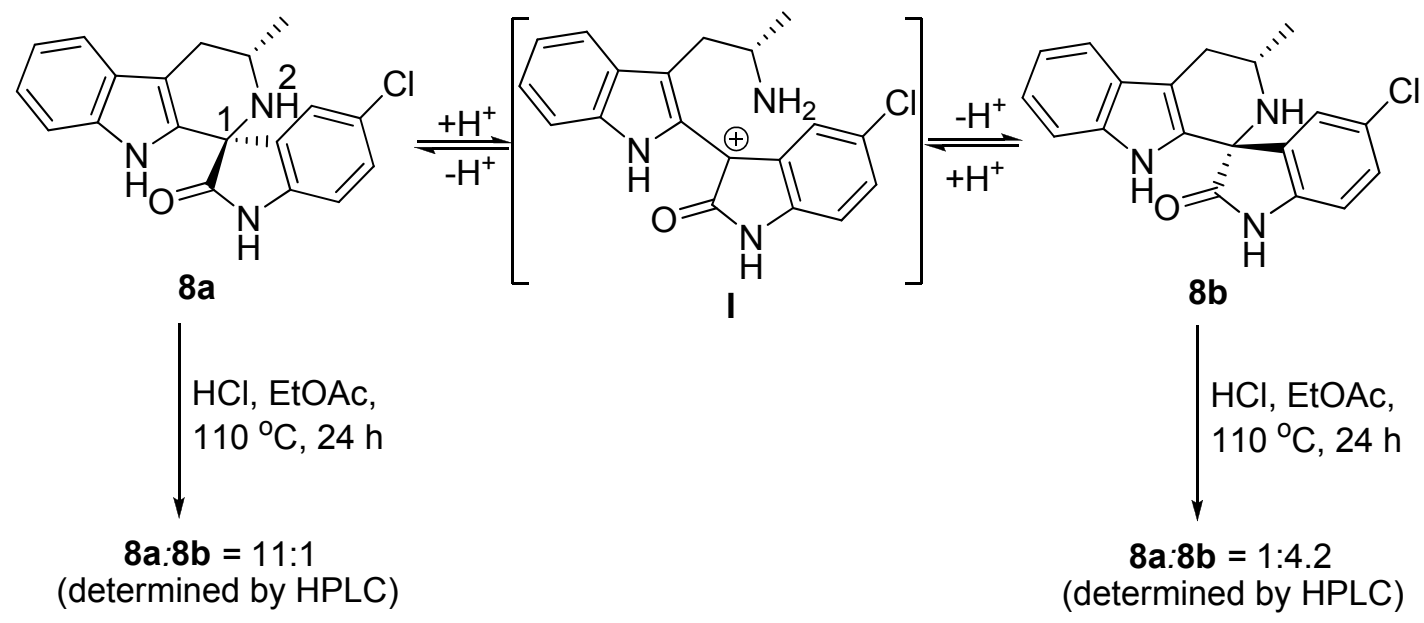

\section{Experimental}

\subsection{Materials and Reagents}

Reagents and solvents were purchased from Aldrich, Acros, or other commercial sources and used without further purification. Thin layer chromatography (TLC) was performed on precoated silica gel $60 \mathrm{~F}_{254}$ plates from Merck. Compounds were visualized under UV light, ninhydrin, or phosphomolybdic acid (PMA) stain. NMR spectra were obtained on a Varian $300 \mathrm{MHz}$ Mercury NMR using $\mathrm{CDCl}_{3}$, and DMSO- $d_{6}$ as solvents. Compound purity was determined by LC/MS and HPLC and carried out on an Agilent LC110 HPLC equipped with a Waters Symmetry Shield RP18, 3.5 $\mu \mathrm{m}, 4.6 \times 150 \mathrm{~mm}$ column using a gradient $(13 \mathrm{~min})$ of $95: 5 \mathrm{H}_{2} \mathrm{O}(0.1 \%$ formic acid $): \mathrm{CH}_{3} \mathrm{CN}$ to $5: 95 \mathrm{H}_{2} \mathrm{O}(0.1 \%$ formic acid): $\mathrm{CH}_{3} \mathrm{CN}$. The purity of all compounds reported were $>95 \%$ measured at $254 \mathrm{~nm}$. The melting point was measured with BÜCHI B-540.

\subsection{Synthesis of Imines $4 Z, 4 E$, and $6 Z$}

(Z)-3-[(2-1H-Indole-4-yl)isopropylimino]-5-chloroindolin-2-one (4Z). Methyltryptamine (1, $100.0 \mathrm{mg}$, $0.57 \mathrm{mmol})$ and 5-chloroisatin $(2,104.2 \mathrm{mg}, 0.57 \mathrm{mmol})$ were dissolved in dry ethanol $(0.6 \mathrm{~mL})$ in a sealed tube. The resulting clear orange red solution was stirred and heated at $80{ }^{\circ} \mathrm{C}$ for $1.5 \mathrm{~h}$. A yellow precipitate was observed after $40 \mathrm{~min}$ of stirring. After completion of the reaction, the precipitate was collected via filtration, washed with cold ethanol and dried under vacuum. The title compound was isolated as a yellow powder (113.0 mg, $58 \%$ yield). $4 Z$ : m.p. $181.3-182.0{ }^{\circ} \mathrm{C}$; IR (film): $v_{\max }=1707 \mathrm{~cm}^{-1}$; ${ }^{1} \mathrm{H}-\mathrm{NMR}\left(\mathrm{DMSO}-d_{6}\right): \delta=10.98$ (br.s., $\left.1 \mathrm{H}\right), 10.76(\mathrm{~s}, 1 \mathrm{H}), 7.63(\mathrm{~d}, J=7.5 \mathrm{~Hz}, 1 \mathrm{H}), 7.41-7.46(\mathrm{~m}, 1 \mathrm{H})$, $7.40(\mathrm{~d}, J=2.1 \mathrm{~Hz}, 1 \mathrm{H}), 7.30(\mathrm{~d}, J=7.8 \mathrm{~Hz}, 1 \mathrm{H}), 7.10(\mathrm{~d}, J=2.1 \mathrm{~Hz}, 1 \mathrm{H}), 7.03(\mathrm{ddd}, J=8.1,7.2,1.2 \mathrm{~Hz}$, $1 \mathrm{H}), 6.93(\mathrm{ddd}, J=8.1,7.2,1.2 \mathrm{~Hz}, 1 \mathrm{H}), 6.84$ (dd, $J=8.1,1.2 \mathrm{~Hz}, 1 \mathrm{H}), 5.56-5.66(\mathrm{~m}, 1 \mathrm{H}), 2.88-3.01$ $(\mathrm{m}, 2 \mathrm{H}), 1.19 \mathrm{ppm}(\mathrm{d}, J=6.0 \mathrm{~Hz}, 3 \mathrm{H}) ;{ }^{13} \mathrm{C}-\mathrm{NMR}$ (DMSO- $\left.d_{6}\right): \delta=160.2,150.1,140.3,135.7,131.8$, $128.3,127.5,123.4,122.2,122.1,119.0,118.9,113.0,112.9,110.6,110.5,56.2,33.8,21.3$ ppm.

(E)-3-[(2-1H-Indole-4-yl)isopropylimino]-5-chloroindolin-2-one (4E). Methyltryptamine (1, $100.0 \mathrm{mg}$, $0.57 \mathrm{mmol})$ and 5 -chloroisatin $(2,104.2 \mathrm{mg}, 0.57 \mathrm{mmol})$ were dissolved in dry ethanol $(0.2 \mathrm{~mL})$ in a 
sealed tube. The resulting clear orange red solution was stirred and heated at $80{ }^{\circ} \mathrm{C}$ for $1 \mathrm{~h}$. A yellow precipitate was observed after 5 min of stirring. After completion of the reaction, the precipitate was collected via filtration, washed with cold ethanol and dried under vacuum. The title compound was isolated as a bright yellow powder (113.0 mg, 58\% yield). $4 E$ : m.p. $168.0-169.2{ }^{\circ} \mathrm{C}$; IR (film): $v_{\max }=1728 \mathrm{~cm}^{-1} ;{ }^{1} \mathrm{H}-\mathrm{NMR}$ (DMSO- $\left.d_{6}\right): \delta=10.93$ (br.s., $\left.1 \mathrm{H}\right), 10.77(\mathrm{~s}, 1 \mathrm{H}), 7.59(\mathrm{~d}, J=8.1 \mathrm{~Hz}, 1 \mathrm{H}), 7.53$ $(\mathrm{d}, J=2.1 \mathrm{~Hz}, 1 \mathrm{H}), 7.37(\mathrm{dd}, J=8.4,2.1 \mathrm{~Hz}, 1 \mathrm{H}), 7.28(\mathrm{ddd}, J=7.8,1.2,1.2 \mathrm{~Hz}, 1 \mathrm{H}), 7.10(\mathrm{~d}, J=2.1 \mathrm{~Hz}$, $1 \mathrm{H}), 7.03(\mathrm{td}, J=7.5,1.2 \mathrm{~Hz}, 1 \mathrm{H}), 6.96(\mathrm{ddd}, J=7.8,6.6,1.2 \mathrm{~Hz}, 1 \mathrm{H}), 6.85(\mathrm{~d}, J=8.4 \mathrm{~Hz}, 1 \mathrm{H}), 4.57-4.69$ $(\mathrm{m}, 1 \mathrm{H}), 2.97-3.14(\mathrm{~m}, 2 \mathrm{H}), 1.33 \mathrm{ppm}(\mathrm{d}, J=6.2 \mathrm{~Hz}, 3 \mathrm{H}) ;{ }^{13} \mathrm{C}-\mathrm{NMR}\left(\mathrm{DMSO}-d_{6}\right): \delta=158.2,151.0$, $142.3,135.6,131.9,127.7,127.3,126.0,122.2,119.2,118.3,117.2,112.9,112.4,111.8,110.5,58.9$, $33.6,20.6 \mathrm{ppm}$.

(Z)-3-[(2-1H-Indole-4-yl)isopropylimino]-4-chloroindolin-2-one (6Z). Methyltryptamine (1, $100.0 \mathrm{mg}$, $0.57 \mathrm{mmol})$ and 4-chloroisatin $(5,104.2 \mathrm{mg}, 0.57 \mathrm{mmol})$ were dissolved in dry ethanol $(0.6 \mathrm{~mL})$ in a sealed tube. The resulting clear orange solution was stirred and heated at $80{ }^{\circ} \mathrm{C}$ for $2.5 \mathrm{~h}$. After completion of the reaction, the precipitate was collected via filtration, washed with cold ethanol and dried under vacuum. The title compound was isolated as a yellow powder $(107.3 \mathrm{mg}, 0.32 \mathrm{mmol}, 55 \%$ yield). 6Z: m.p. $169.4-170.3{ }^{\circ} \mathrm{C}$; IR (film): $v_{\max }=1708 \mathrm{~cm}^{-1} ;{ }^{1} \mathrm{H}-\mathrm{NMR}$ (DMSO- $d_{6}$ ): $\delta=11.05$ (br.s., $1 \mathrm{H}), 10.76(\mathrm{~s}, 1 \mathrm{H}), 7.66(\mathrm{~d}, J=7.5 \mathrm{~Hz}, 1 \mathrm{H}), 7.27-7.38(\mathrm{~m}, 2 \mathrm{H}), 7.13(\mathrm{~d}, J=2.1 \mathrm{~Hz}, 1 \mathrm{H}), 6.99-7.06$ (m, 2H), $6.93(\mathrm{ddd}, J=7.8,7.2,1.2 \mathrm{~Hz}, 1 \mathrm{H}), 6.78(\mathrm{dd}, J=7.8,1.2 \mathrm{~Hz}, 1 \mathrm{H}), 5.63-5.73(\mathrm{~m}, 1 \mathrm{H}), 2.89-3.04$ $(\mathrm{m}, 2 \mathrm{H}), 1.20 \mathrm{ppm}(\mathrm{d}, J=6.0 \mathrm{~Hz}, 3 \mathrm{H}) ;{ }^{13} \mathrm{C}-\mathrm{NMR}\left(\mathrm{DMSO}-d_{6}\right): \delta=158.5,151.0,145.7,136.1,133.4$, $128.9,127.5,123.8,123.5,120.7,118.7,118.1,117.4,111.7,111.2,109.2,55.8,34.0,21.7$ ppm.

\subsection{General Procedure for Cyclization of Imines at Different Temperatures}

To the solution of the imines $(20 \mathrm{mg}, 0.06 \mathrm{mmol})$ in ethyl acetate $(1 \mathrm{~mL})$ was added hydrochloric acid $\left(0.15 \mathrm{~mL}, 4 \mathrm{~N}\right.$ in 1,4-dioxane, 10.0 eq.) at $-78{ }^{\circ} \mathrm{C}$, room temperature or $110{ }^{\circ} \mathrm{C}$ (in sealed tube) and the reaction mixture was stirred for $1 \mathrm{~h}, 25 \mathrm{~min}$ or $10 \mathrm{~min}$ respectively. The reaction mixture was quneched by adding $1 \mathrm{~N}$ aqueous sodium hydroxide solution $(3 \mathrm{~mL})$ and aqueous phase was extracted with ethyl acetate $(2 \times 8 \mathrm{~mL})$. The combined organic phases were dried over $\mathrm{Na}_{2} \mathrm{SO}_{4}$, filtered, and concentrated in vacuo. The residue was purified by flash column chromatography.

(trans)-5'-Chloro-3-methyl-2,3,4,9-tetrahydrospiro[ $\beta$-carboline-1,3'-indol]-2'(1'H)-one (3a): $\mathrm{m} / \mathrm{z}$ (ESI): $[\mathrm{M}+\mathrm{H}]^{+} 338 ;{ }^{1} \mathrm{H}-\mathrm{NMR}\left(\mathrm{DMSO}-d_{6}\right): \delta=10.45(\mathrm{~s}, 1 \mathrm{H}), 10.42(\mathrm{~s}, 1 \mathrm{H}), 7.43(\mathrm{~d}, J=7.2 \mathrm{~Hz}, 1 \mathrm{H}), 7.31(\mathrm{dd}$, $J=8.4,2.4 \mathrm{~Hz}, 1 \mathrm{H}), 7.16(\mathrm{~d}, J=7.2 \mathrm{~Hz}, 1 \mathrm{H}), 7.03(\mathrm{~d}, J=2.4 \mathrm{~Hz}, 1 \mathrm{H}), 6.99(\mathrm{~m}, 1 \mathrm{H}), 6.92(\mathrm{~d}, J=8.4 \mathrm{~Hz}$, 2H), $3.93(\mathrm{~m}, 1 \mathrm{H}), 3.05(\mathrm{~d}, J=6.3 \mathrm{~Hz}, 1 \mathrm{H}), 2.79(\mathrm{dd}, J=15.0,3.6 \mathrm{~Hz}, 1 \mathrm{H}), 2.41(\mathrm{dd}, J=15.0,10.5 \mathrm{~Hz}$, $1 \mathrm{H}), 1.17 \mathrm{ppm}(\mathrm{d}, J=6.3 \mathrm{~Hz}, 3 \mathrm{H}) ;{ }^{13} \mathrm{C}-\mathrm{NMR}\left(\mathrm{DMSO}-d_{6}\right): \delta=178.5,141.6,136.4,134.4,131.0$, $128.9,126.4,125.5,124.8,121.1,118.4,117.8,111.1,111.0,61.9,44.3,29.6,21.7$ ppm.

(cis)-5'-Chloro-3-methyl-2,3,4,9-tetrahydrospiro[ $\beta$-carboline-1,3'-indol]-2'(1'H)-one (3b): $\mathrm{m} / z$ (ESI): $[\mathrm{M}+\mathrm{H}]^{+} 338 ;{ }^{1} \mathrm{H}-\mathrm{NMR}\left(\mathrm{DMSO}-d_{6}\right): \delta=10.80(\mathrm{~s}, 1 \mathrm{H}), 10.59(\mathrm{~s}, 1 \mathrm{H}), 7.45(\mathrm{~d}, J=6.9 \mathrm{~Hz}, 1 \mathrm{H}), 7.30(\mathrm{dd}$, $J=8.4,2.1 \mathrm{~Hz}, 1 \mathrm{H}), 7.18(\mathrm{~d}, J=2.1 \mathrm{~Hz}, 1 \mathrm{H}), 7.15(\mathrm{~s}, 1 \mathrm{H}), 7.03(\mathrm{td}, J=7.5,1.5 \mathrm{~Hz}, 1 \mathrm{H}), 6.94-7.00$ (m, 2H), $3.47(\mathrm{~m}, 1 \mathrm{H}), 2.92(\mathrm{dd}, J=15.3,3.9 \mathrm{~Hz}, 1 \mathrm{H}), 2.42(\mathrm{dd}, J=15.3,10.5 \mathrm{~Hz}, 1 \mathrm{H}), 2.31(\mathrm{~d}, J=9.0 \mathrm{~Hz}$, 
1H), $1.23 \mathrm{ppm}(\mathrm{d}, J=6.3 \mathrm{~Hz}, 3 \mathrm{H}) ;{ }^{13} \mathrm{C}-\mathrm{NMR}\left(\mathrm{DMSO}-d_{6}\right): \delta=177.1,140.6,136.4,135.9,130.7$, $128.5,126.1,125.7,124.3,121.3,118.4,117.8,111.6,111.1,110.8,62.9,45.8,29.7,22.0$ ppm.

(trans)-4'-Chloro-3-methyl-2,3,4,9-tetrahydrospiro[ $\beta$-carboline-1,3'-indol]-2'(1'H)-one (7a): $\mathrm{m} / \mathrm{z}$ (ESI): $[\mathrm{M}+\mathrm{H}]^{+} 338 ;{ }^{1} \mathrm{H}-\mathrm{NMR}\left(\mathrm{DMSO}-d_{6}\right): \delta=10.55$ (br.s., $\left.1 \mathrm{H}\right), 10.50(\mathrm{~s}, 1 \mathrm{H}), 7.43(\mathrm{~d}, J=7.2 \mathrm{~Hz}, 1 \mathrm{H}), 7.29$ (t, $J=7.8 \mathrm{~Hz}, 1 \mathrm{H}), 7.17(\mathrm{~d}, J=7.2 \mathrm{~Hz}, 1 \mathrm{H}), 6.94-7.05(\mathrm{~m}, 2 \mathrm{H}), 6.85-6.94$ (m, 2H), 3.94 (m, 1H), 2.84 $(\mathrm{dd}, J=15.0,3.6 \mathrm{~Hz}, 1 \mathrm{H}), 2.65(\mathrm{~d}, J=6.0 \mathrm{~Hz}, 1 \mathrm{H}), 2.36(\mathrm{dd}, J=15.0,10.5 \mathrm{~Hz}, 1 \mathrm{H}), 1.19 \mathrm{ppm}(\mathrm{d}$, $J=6.6 \mathrm{~Hz}, 3 \mathrm{H}$ ); ${ }^{13} \mathrm{C}-\mathrm{NMR}\left(\mathrm{DMSO}-d_{6}\right): \delta=177.5,144.8,136.4,130.9,130.5,129.4,128.2,126.3$, $122.4,120.9,118.2,117.7,111.3,111.1,108.7,62.3,44.3,29.7,21.8$ ppm.

(cis)-4'-Chloro-3-methyl-2,3,4,9-tetrahydrospiro[ $\beta$-carboline-1,3'-indol]-2'(1'H)-one (7b): $\mathrm{m} / z$ (ESI): $[\mathrm{M}+\mathrm{H}]^{+} 338 ;{ }^{1} \mathrm{H}-\mathrm{NMR}\left(\mathrm{DMSO}-d_{6}\right): \delta=10.83$ (br.s., $\left.1 \mathrm{H}\right), 10.50(\mathrm{~s}, 1 \mathrm{H}), 7.44(\mathrm{~d}, J=7.2 \mathrm{~Hz}, 1 \mathrm{H}), 7.28$ $(\mathrm{d}, J=8.1 \mathrm{~Hz}, 1 \mathrm{H}), 7.17(\mathrm{~d}, J=7.5 \mathrm{~Hz}, 1 \mathrm{H}), 6.90-7.06(\mathrm{~m}, 4 \mathrm{H}), 3.80(\mathrm{~m}, 1 \mathrm{H}), 2.92$ (dd, $J=15.0$, $3.9 \mathrm{~Hz}, 1 \mathrm{H}), 2.41$ (dd, $J=15.3,10.2 \mathrm{~Hz}, 1 \mathrm{H}), 1.23 \mathrm{ppm}(\mathrm{d}, J=6.0 \mathrm{~Hz}, 3 \mathrm{H}) ;{ }^{13} \mathrm{C}-\mathrm{NMR}$ (DMSO- $\left.d_{6}\right)$ : $\delta=177.3,144.4,136.4,130.5,130.5,130.1,129.1,126.2,122.9,121.1,118.2,117.8,111.3,111.1$, 109.2, 63.6, 46.9, 29.9, $22.2 \mathrm{ppm}$.

\section{Conclusions}

In summary, an explanation of the high diastereoselectivity observed in the Pictet-Spengler reaction of the new class of antimalarials exemplified by the candidate NITD609 is proposed. A careful mechanistic study of the reaction, including the isolation and characterization of the imine intermediates, suggests that under kinetic conditions, the geometry of the imine and subsequent release of $A^{1,3}$ strain in the six-membered transition state determines the cis/trans ratio and thus the diastereoselectivity of the products; under thermodynamic conditions, the diastereoselective outcome is independent of the imine geometry and instead controlled by fast equilibration through a bis-spiro intermediate. The subsequent ring expansion forms a six-membered transition state which is governed by the release of $\mathrm{A}^{1,3}$ strain. The lower energy intermediate leads to the formation of the favored trans product. This knowledge has proven helpful in the large-scale synthesis of our clinical candidate NITD609.

\section{Supplementary Materials}

Supplementary materials can be accessed at: http://www.mdpi.com/1420-3049/17/9/10131/s1.

\section{Acknowledgments}

Funding is acknowledged from the Medicines for Malaria Venture, a translational research grant (WTO78285) from the Wellcome Trust and the Singapore Economic Development Board. We thank Thierry T. Diagana for the support of this work.

\section{References and Notes}

1. World Health Organization (WHO). World Malarial Report 2011. Available online: http://www.who.int/malaria/world_malaria_report_2011/en/index.html (accessed on 14 August 2012). 
2. Noedl, H.; Se, Y.; Schaecher, K.; Smith, B.L.; Socheat, D.; Fukuda, M.M. Evidence of artemisinin-resistant malaria in western Cambodia. N. Engl. J. Med. 2008, 359, 2619-2620.

3. Dondorp, A.M.; Yeung, S.; White, L.; Nguon, C.; Day, N.P.; Socheat, D.; von Seidlein, L. Artemisinin resistance: Current status and scenarios for containment. Nat. Rev. Microbiol. 2010, 8, 272-280.

4. World Health Organization (WHO). Update on artemisinin resistance-September 2011. Available online: http:/www.who.int/malaria/diagnosis_treatment/resistance/ updateonartemsininresistancesept2011.pdf (accessed on 14 August 2012).

5. Rottmann, M.; McNamara, C.; Yeung, B.K.S.; Lee, M.C.S.; Zou, B.; Russell, B.; Seitz, P.; Plouffe, D.M.; Dharia, N.V.; Tan, J.; et al. Spiroindolones, a new and potent chemotype for the treatment of malarial. Science 2010, 329, 1175-1180.

6. Yeung, B.K.S.; Zou, B.; Rottmann, M.; Lakshminarayana, S.B.; Ang, S.H.; Leong, S.Y.; Tan, J.; Wong, J.; Keller-Maerki, S.; Fischli, C.; et al. Spirotetrahydro $\beta$-carbolines (Spiroindolones): A new class of potent and orally efficacious compounds for the treatment of malaria. J. Med. Chem. 2010, 53, 5155-5164.

7. Cox, E.D.; Cook, J.M. The Pictet-Spengler condensation: A new direction for an old reaction. Chem. Rev. 1995, 95, 1797-1842.

8. Cox, E.D.; Hamaker, L.K.; Li, M.; Yu, P.; Czerwinksi, K.M.; Deng, L.; Bennett, D.W.; Cook, J.M. Enantiospecific formation of Trans 1,3-disubstituted tetrahydro- $\beta$-carbolines by the Pictet-Spengler reaction and conversion of cis diastereomers into their trans counterparts by scission of the C-1/N-2 bond. J. Org. Chem. 1997, 62, 44-61.

9. Lorenz, M.; Van Linn, M.L.; Cook, J.M. The asymmetric Pictet-Spengler reaction. Curr. Org. Synth. 2010, 7, 189-223.

10. Fang, H.; Wu, X.; Nie, L.; Dai, X.; Chen, J.; Cao, W.; Zhao, G. Diastereoselective syntheses of indoloquinolizidines by a Pictet-Spengler/Lactamization cascade. Org. Lett. 2010, 12, 5366-5369.

11. Cheng, D.; Wu, H.; Tian, S. Catalytic asymmetric Pictet-Spengler-Type reaction for the Synthesis of optically active indolo[3,4-cd][1]benzazepines. Org. Lett. 2011, 13, 5636-5639.

12. Rashid, N.; Alam, S.; Hasan, M.; Khan, N.; Khan, K.M.; Duddeck, H.; Pescitelli, G.; Kenéz, A.; Antus, S.; Kurtán, T. Cis-diastereoselectivity in Pictet-Spengler reactions of L-tryptophan and electronic circular dichrosim studies. Chirality 2012, doi:10.1002/chir.22070.

13. Schönherr, H.; Leighton, J.L. Direct and highly enantioselective Iso-Pictet-Spengler reactions with $\alpha$-ketoamides: Access to underexplored indole core structures. Org. Lett. 2012, 14, 2610-2613.

14. Duce, S.; Pesciaioli, F.; Gramigna, L.; Bernardi, L.; Mazzanti, A.; Ricci, A.; Bartoli, G.; Bencivenni, G. An easy entry to optically active spiroindolinones: Chiral Brønsted acid-catalysed Pictet-Spengler reactions of isatins. Adv. Synth. Catal. 2011, 353, 860-864.

15. Badillo, J.J.; Silva-García, A.; Shupe, B.H.; Fettinger, J.C.; Franz, A.K. Enantioselective Pictet-Spengler reactions of isatins for the synthesis of spiroindolones. Tetrahetron Lett. 2011, 52, 5550-5553.

16. Semonov, B.B.; Novikov, K.A.; Azev, V.N.; Kachala, V.V. Diastereoselective synthesis of 1,1-disubstituted 4-phenyl-2,3,4,9-tetrahydrospiro- $\beta$-carbolines from $\beta$-phenyltryptamine and isatin derivatives. Russ. Chem Bull. 2005, 54, 988-991. 
17. Pogosyan, S.A.; Grigoryan, N.P.; Paronikyan, R.G. Synthesis and anticonvulsant activity of dihydrochlorides of indoline-3'spiro-1-(1,2,3,4-tetrahydro- $\beta$-carboline derivatives. Pharm. Chem. J. 2007, 31, 527-528.

18. Grigoryan, N.P.; Pogosyan, S.A.; Paronikyan, R.G. Synthesis and anti-apasmodic activity of hydrochlorids 2'-oxo-(5'-bromindolin)-3'-spiro-1-(1.2.3.4-tetrahydro)- $\beta$-carbolines and indoloasepins. Armen. Chem. J. 2005, 58, 100-104.

19. Bailey, P.D.; Beard, M.A.; Phillips, T.R. Unexpected cis selectivity in the Pictet-Spengler reaction. Tetrahedron Lett. 2009, 50, 3645-3647.

20. Bailey, P.D.; Hollinshead, S.P.; McLay, N.R.; Morgan, K.; Palmer, S.J.; Prince, S.N.; Reynolds, C.D.; Wood, S.D. Diastereo- and enantio-selectivity in the Pictet-Spengler reaction. J. Chem. Soc. Perkin Trans. 1 1993, 431-439.

21. Bailey, P.D. Direct proof of the involvement of a spiro intermediate in the Pictet-Spengler reaction. J. Chem. Res. (S) 1987, 6, 202-203.

22. Zou, H.; Han, D.; Lao, X.; Cook, J.M. First regiospecific, enantiospecific total synthesis of gardnerine and gargnutine. Tetrahedron Lett. 2005, 46, 4219-4224.

23. Kumpati, H.J.; van Linn, M.L.; Kabir, M.S.; Försterling, F.H.; Deschamps, J.R.; Cook, J.M. Study of the cis to trans isomerization of 1-phenyl-2,3-disubstituted tetrahydro-beta-carbolines: Evidence for the carbocation-mediated mechanism. J. Org. Chem. 2009, 74, 2771-2779.

24. Van Linn, M.L.; Cook, J.M. Mechanistic studies on the cis to trans epimerization of trisubstituted 1,2,3,4-tetrahydro-beta-carbolines. J. Org. Chem. 2010, 75, 3587-3599.

25. Kuo, F.M.; Tseng, M.C.; Yen, Y.H.; Chu, Y.H. Microwave accelerated Pictet-Spengler reactions of tryptophan with ketones directed toward the preparation of 1,1-disubstituted alkaloids. Tetrahedron 2004, 60, 12075-12084.

26. Mangion, I.K.; Northrup, A.B.; MacMillan, D.W.C. The importance of iminium geometry control in enamine catalysis: Identification of a new catalyst architecture for aldehyde-aldehyde couplings. Angew. Chem. Int. Ed. 2004, 43, 6722-6724.

27. Guo, Q.; Liu, Y.; Li, X.; Zhong, L.; Peng, Y. Enantioselective and solvent-controlled diastereoselective Mannich reaction of isatin imines with hydroxyacetone: Synthesis of 3-substituted 3-aminooxindoles. J. Org. Chem. 2012, 77, 3589-3594.

28. Parasuk, W.; Parasuk, V. Theoretical investigations on the stereoselectivity of the proline catalyzed Mannich reaction in DMSO. J. Org. Chem. 2008, 73, 9388-9392.

29. Abadi, A.H.; Abou-Seri, S.M.; Abdel-Rahman, D.E.; Klein, C.; Lozach, O.; Meijer, L. Synthesis of 3-substituted-2-oxoindole analogues and their evaluation as kinase inhibitors, anticancer and antiangiogenic agents. Eur. J. Med. Chem. 2006, 41, 296-305.

30. Under standard HPLC conditions both $\mathbf{4 E}$ and $\mathbf{4 Z}$ decomposed rapidly back to starting materials.

Sample Availability: Samples of the compounds $4 Z, 4 E, 6 Z, 3 a, 3 b, 7 a$ and $7 \mathbf{b}$ are available from the authors.

(C) 2012 by the authors; licensee MDPI, Basel, Switzerland. This article is an open access article distributed under the terms and conditions of the Creative Commons Attribution license (http://creativecommons.org/licenses/by/3.0/). 